\title{
POSITION 97 OF HLA-B, A RESIDUE IMPLICATED IN ANKYLOSING SPONDYLITIS PATHOGENESIS, PLAYS A KEY ROLE IN CELL SURFACE FREE HEAVY CHAIN EXPRESSION
}

Liye Chen, ${ }^{1 *}$ Hui Shi, ${ }^{1 *}$ Jack Yuan, ${ }^{1}$ Paul Bowness ${ }^{1}$

${ }^{1}$ Nuffield Department of Orthopaedics, Rheumatology and Musculoskeletal Sciences, University of Oxford, Oxford, UK

* LC and HS contributed equally to this work.

Running title: Position 97 of HLA-B affects cell surface expression

Key words: Ankylosing Spondylitis, Gene Polymorphism, Autoimmunity

Word Count: 2974 Max=3000 
Abstract (word count: 248, Max=250)

\section{Objective}

Association of position 97 (P97) residue polymorphisms in human leukocyte antigen (HLA)-B, including HLA-B*27, with Ankylosing Spondylitis (AS) has recently been reported. We studied the effect of P97 variations on cell surface expression of the AS-associated HLA-B*27 and HLA-B*51, and the AS-protective HLA-B*7.

\section{Methods}

Flow cytometry was used to measure surface expression of HLA-B*27 in C1R/HeLa cells expressing HLA-B*27 (N97) and six mutants at P97 (N97T, N97S, N97V, N97R, N97W and N97D). TAP-deficient T2, Tapasin-deficient 220, $\beta 2 \mathrm{~m}$-deficient HCT15 and ERAP1 or $\beta 2 \mathrm{~m}$ CRISPR/Cas9-knockout HeLa cells were used to provide evidence for specific protein interactions. Surface expression of HLA-B*7/HLA-B*51 P97 mutants was also studied.

\section{Results}

Mutation of HLA-B*27 P97 to the AS risk residue Threonine increased cell surface free heavy chain (FHC) expression. Protective residues (Serine or Valine) and non AS-associated residues (Arginine or Tryptophan) did not alter FHC expression. The N97D mutation reduced expression of conventional and FHC forms of HLA-B*27. Differences in FHC expression levels between HLA-B*27, HLA-B*27-N97T and HLA-B*27-N97D were dependent on the presence of functional $\beta 2 \mathrm{~m}$. HLA-B*7, which has an AS-protective Serine at P97, expressed lower levels of FHC than HLA-B*27 or HLA-B*51. Introduction of Asparagine at P97 of both HLA-B*7 and HLA-B*51 increased FHC expression. 


\section{Conclusion}

The nature of P97 residue affects surface expression of HLA-B*27, B*7 and B*51; with ASassociated residues giving rise to higher FHC expression levels. The association of P97 amino acid polymorphisms with AS could be, at least in part, explained by its effect on HLA-B*27 FHC cell surface expression. 


\section{INTRODUCTION}

Ankylosing Spondylitis (AS) is a common form of inflammatory arthritis that is strongly associated with possession of the human leukocyte antigen (HLA)-B*27. ${ }^{1}$ A recent finemapping study of the major histocompatibility complex (MHC) has reported the strong association of AS with carriage of particular amino acids at position 97 (P97) in HLA-B. ${ }^{2}$ Indeed, conditional analysis suggested that P97 contributed much of the genetic risk ascribed to HLA-B*27. Six amino acid variants at P97 of HLA-B with differing effects on AS risk were identified and are shown in table 1. Asparagine (N) and Threonine (T) conferred increased risk of AS. Serine (S) and Valine (V) were protective residues, and no association was found for Arginine (R) and Tryptophan (W). Located in the $\alpha 2$ domain of HLA-B*27, P97 lies within a $\beta$ sheet that contributes to the $\mathrm{C} / \mathrm{F}$ peptide-binding pocket, but may also contact $\beta$ 2-microglobulin

( $\beta 2 \mathrm{~m}$ ) (figure 1A). ${ }^{34}$ Notably, the adjacent position 96 (P96) has indeed been shown to contact $\beta 2 \mathrm{~m}$ in molecular-graphics analysis using crystal structures of HLA-A2.1 and HLA-Aw68.1. ${ }^{5}$ Mutation of N at P97 to Aspartic acid (D) has been reported to decrease cell surface expression of HLA-B*27:04 free heavy chains (FHCs) and classical complexes. ${ }^{6}$ 
Table 1 Association of P97 residues of HLA-B with AS

\begin{tabular}{|c|c|c|c|c|}
\hline P97 residues & Association with AS & *Odds ratio & $* P$ value & $\begin{array}{l}\text { Examples of } \\
\text { HLA-B allele }\end{array}$ \\
\hline $\mathrm{N}$ & Risk & 16.51 & $<10^{-300}$ & $* 27: 05$ \\
\hline $\mathrm{T}$ & Risk & 1.12 & $4.5 \times 10^{-3}$ & $\begin{array}{l}* 51: 01 \\
* 13: 02\end{array}$ \\
\hline $\mathrm{R}$ & Non-associated & 1 & 1 & $\begin{array}{l}* 15: 01 \\
* 40: 01 \\
* 47: 01\end{array}$ \\
\hline $\mathrm{W}$ & Non-associated & 1 & 0.95 & *14:01 \\
\hline $\mathrm{S}$ & Protective & 0.86 & $4.81 \times 10^{-8}$ & $\begin{array}{l}* 07: 02 \\
* 40: 02\end{array}$ \\
\hline V & Protective & 0.68 & $1.41 \times 10^{-8}$ & $* 57: 01$ \\
\hline $\mathrm{D}$ & Synthetic & N/A & N/A & N/A \\
\hline
\end{tabular}

* Statistics from Cortes A. et al. Nat Commun, 2015, Fisher's exact test used for P value. The HLA-B allotypes investigated in current study, HLA-B*27:05, HLA-B*51:01 and HLA-B*07:01, are highlighted in bold. Of note, Aspartic acid (D) is not present in P97 of HLA-B.

The mechanism by which HLA-B*27 confers AS disease susceptibility remains unclear. Presentation of arthritogenic peptides by HLA*B27 to CD8+ T cells has been hypothesized. 
However, this hypothesis is challenged by the finding that CD8+ T cells are not essential to the pathogenesis of arthritis in the HLA-B*27-trangenic rat model. ${ }^{78}$ HLA-B*27 has been shown to both misfold in the endoplasmic reticulum (ER), and also to be expressed as FHC forms on the cell surface. ${ }^{9-13}$ Cell surface HLA-B*27 FHCs can bind to killer cell immunoglobulin-like receptors including KIR3DL2, which is expressed on natural killer (NK) cells and CD4+ T cells, and can promote Th17 responses in AS patients. ${ }^{14-16}$ We hypothesized that variations of residues at P97 might contribute to AS pathogenesis through altering cell surface HLA-B*27 FHC expression.

To test this hypothesis, we studied the effect of P97 residue mutations on HLA-B*27:05 (hereafter referred to as HLA-B*27) FHC expression. CRISPR-Cas9-knockout, siRNA-silenced or naturally-deficient cells were used to study the relative effects of proteins involved in the antigen presentation pathway. Here we show that the nature of the P97 residues affects cell surface expression of both HLA-B*27 FHCs and classical complexes, and we provide evidence that $\beta 2 \mathrm{~m}$ plays an important role. Cell surface expression of HLA-B*7:02 and HLA-B*51:01 (hereafter referred to as HLA-B*7 and HLA-B*51 respectively) is also affected by P97.

\section{MATERIALS AND METHOD}

\section{Cell lines}

HeLa and C1R cells expressing HLA-B*27 and six mutants at P97 (N97T, N97S, N97V, N97R, N97W and N97D) were generated using lentiviral constructs described previously. ${ }^{17} \mathrm{HeLa}$ and C1R cells expressing HLA-B*7 and its P97 mutants (S97N, S97T and S97D), HeLa and 221 
cells expressing HLA-B*51 and its P97 mutants (T97N and T97D) were also generated using lentiviruses. TAP-deficient T2 and tapasin-deficient LBL721.220 (220) lymphoblastoid cells, and the $\beta 2 \mathrm{~m}$-deficient HCT15 cancer cell line have been previously described. ${ }^{18}{ }^{19}$ All cell lines were cultured in RPMI-1640 supplemented with $10 \%$ fetal bovine serum, $0.1 \mathrm{mg} / \mathrm{ml}$ of streptomycin, and 100 units/ml of penicillin (R10).

\section{Flow cytometry}

The HC-10 antibody (mouse IgG2a, specific for HLA class I free heavy chains), was used to stain cell surface expression of HLA-B*27, B*7 and B*51 free heavy chains. ${ }^{20}$ The ME-1 antibody (mouse IgG1, specific for classical $\beta 2 \mathrm{~m}$-associated HLA-B27, B7, B42, B67, B73 and Bw22) was used to measure classical HLA-B*27 and B*7 complexes on the cell surface. W6/32 antibody (mouse IgG2a, specific for classical $\beta 2 \mathrm{~m}$-associated HLA-A, B or C) was used to stain surface-expressed classical HLA-B*51 complexes in C1R and 221 cells. APC- or PEconjugated anti-mouse IgG antibody was used as secondary antibody. Dead cells were excluded using LIVE/DEAD® Fixable Violet Dead Cell Stain Kit (Life Technologies). BD LSRFortessa $^{\mathrm{TM}}$ and Diva software were used. The latter converts channel value into fluorescence intensity using a logarithmic algorithm, therefore geometric mean fluorescence intensity (GMFI) was used to quantify the intensity of HC-10, ME-1 and W6/32 staining.

\section{Plasmid construction}

To generate plasmids expressing P97 mutants, point mutations were delivered into PHR-SIN lentiviral plasmids encoding HLA-B*27, B*7 and B*51 using QuickChange Site-Directed 
Mutagenesis Kit (Agilent Technologies). Primers were designed for generation of HLA-B*27 mutants at P97 (TCTCACACCCTCCAGACGATGTATGGCTGC for N97T, TCTCACACCCTCCAGAGCATGTATGGCTGC for $\quad$ N97S, $\begin{array}{lll}\text { TCTCACACCCTCCAGGTGATGTATGGCTGC for } & \text { N97V, }\end{array}$ $\begin{array}{lll}\text { TCTCACACCCTCCAGAGGATGTATGGCTGC for } & \text { N97R, }\end{array}$

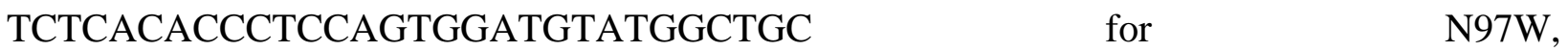
TCTCACACCCTCCAGGATATGTATGGCTGC for N97D). For generation of HLA-B*7 mutants at P97, following primers were used: TCTCACACCCTCCAGAATATGTATGGCTGC for S97N, TCTCACACCCTCCAGACGATGTATGGCTGC for S97T, TCTCACACCCTCCAGGATATGTATGGCTGC for S97D. HLA-B*51 mutants were generated using TCTCACACTTGGCAGAATATGTATGGCTGC (T97N) and TCTCACACTTGGCAGGATATGTATGGCTGC (T97D).

The $\beta 2 \mathrm{~m}$ plasmid was purchased from Origene (SC117632); loss-of-function $\beta 2 \mathrm{~m}-\mathrm{C} 25 \mathrm{~W}$ plasmid was generated using the same kit described above (primer: CAAATTTCCTGAATTGGTATGTGTCTGGG).

\section{Generation of ERAP1- or ß2m -knockout HeLa cells using Cas9 nuclease}

A previously described clustered regularly-interspaced short palindromic repeats (CRISPR)-Cas9 plasmid, pSpCas9(BB)-2A-GFP (PX458), was acquired from Addgene. ${ }^{21}$ sgRNA for ERAP1 or $\beta 2 \mathrm{~m}$ was designed and cloned into the plasmid (ERAP1: CACCGACCCAGACACATAGCAATTC and AAACGAATTGCTATGTGTCTGGGTC, $\beta 2 \mathrm{~m}$ : 
CACCGCTCACTGTGATGGTtATtAG and AAACCTAATAACCATCACAGTGAGC). The PX458-ERAP1 or PX458- $\beta 2 \mathrm{~m}$ plasmid was transfected into HeLa cells using Genejuice (Merck). $\beta 2 \mathrm{~m}$-knockout HeLa cells were further purified using PE-conjugated W6/32 antibody (eBioscience), anti-PE beads and LD columns (Miltenyi).

\section{Statistics}

Results are expressed as mean and standard deviation (figure 1B, 1C, 3B and 4). The statistical significance of differences between means was assessed using an unpaired two-tailed t-test (figure 1B, 1C, 3B and 4). A p value $<0.05$ was considered significant.

\section{RESULTS}

\section{P97 amino acid variants affect HLA-B $* 27$ expression on the cell surface.}

We first investigated the effect of position 97 (P97) residue variations on HLA-B*27 expression in two human cell lines. Both Asparagine (N, found in HLA-B*27) and Threonine (T) are associated with increased risk of AS. ${ }^{2}$ Figure 1B, C shows that mutation of N at P97 in HLA$\mathrm{B} * 27$ to $\mathrm{T}$ increases surface free heavy chain (FHC) expression (measured by the HC-10 antibody) in both C1R and HeLa cells. Notably this occurs without changing the expression level of classical ME-1-reactive HLA-B*27 complexes (see online supplementary figure S1 for FACS plots). In contrast, mutations to protective or un-associated resides do not affect either HC-10 or ME-1 expression (figure 1B, C). Thus N97S, N97R and N97W do not significantly alter levels of HC-10 and ME-1-reactive HLA-B*27. N97V modestly increases HLA-B*27 
FHC expression in C1R but not in HeLa cells. The mutation of $\mathrm{N}$ to Aspartic acid (D) at P97, which is not found in human HLA-B allotypes, has been reported to abolish the expression of HC-10 and ME1-reactive HLA-B*27:04 molecules. ${ }^{6}$ We therefore also studied the N97D HLA$\mathrm{B} * 27: 05$ mutant, and found that this mutation significantly reduced expression of both FHC and classical HLA-B27 complexes on the surface of C1R and HeLa cells (figure 1B, C). These results show that the nature of the amino acid at P97 affects cell surface expression of HLA$\mathrm{B} * 27 \mathrm{FHCs}$ and classical complexes.

We next tried to decipher the mechanisms underlying the effect of P97 on HLA-B*27 expression. Here we focused on comparisons of wild type HLA-B*27 with two mutants that resulted in changes of HLA-B*27 free heavy chain (FHC) expression, N97T and N97D (figure 1B, C). Similar stability of cell surface classical HLA-B*27 between HLA-B*27, N97T and N97D mutants was observed, suggesting that P97 more likely affects maturation or trafficking of HLAB*27 inside cells (see online supplementary figure S2). Following removal of cell surface HLAB*27 complexes using activated papain, both N97D FHCs and classical complexes on the cell surface recovered more slowly than HLA-B*27 (see online supplementary figure S3). Interestingly, N97T did not affect the recovery of cell surface classical HLA-B*27 complexes, but promoted the recovery of FHCs at cell surface. We also found that levels of intracellular HLA-B*27 FHCs were highest in the N97D mutant, followed by N97T, and then wild type HLA-B*27 (see online supplementary figure S4). 
The effect of N97T and N97D mutations on HLA-B*27 expression is largely dependent on B2m, but not TAP, tapasin or ERAP1.

We then sought to identify the proteins that might interact differentially with different P97 residues to affect cell surface HLA-B*27 expression. Both the transporter associated with antigen processing (TAP) and tapasin are key chaperones for the loading of peptide ligands onto MHC class I molecules, and are important for MHC class I expression. ${ }^{22}$ We therefore first tested whether the altered HLA-B*27 FHC expression observed for N97T and N97D mutants was still seen using TAP- and tapasin-deficient cells (figure 2A, B). TAP-deficient T2.B*27 cells did not express HLA-B*27 FHCs and only expressed low level of classical HLA-B*27 complexes when compared to untransfected T2 cells (figure 2A). The N97D mutation nearly abolished expression of classical HLA-B*27 complexes on the cell surface. Significant reduction of HC-10 and ME-1 was found in tapasin-deficient 220 cells expressing HLA-B*27N97D compared to the wildtype (figure 2B). Similar to its effect in C1R and HeLa cells, the N97T mutation increased HLA-B*27 FHC without affecting classical complexes. Deficiency of TAP and tapasin in T2 and 220 respectively was confirmed by western blot (see online supplementary figure S5A, B). Thus the effect of P97 amino acid on HLA-B*27 expression is unchanged in the absence of TAP or tapasin.

Endoplasmic reticulum aminopeptidase 1 (ERAP1) polymorphisms are strongly associated with ankylosing spondylitis (AS) in patients carrying HLA-B*27, ${ }^{1}$ and can promote cell surface expression of HLA-B*27 FHCs. ${ }^{23}$ We therefore asked if the absence of ERAP1 changes the effect of the P97 mutation on HLA-B*27 expression. CRISPR-Cas9 was used to knockout 
endogenous ERAP1 in HeLa cells (see online supplementary figure S5C for western blot showing efficacy of ERAP1 knockout). Figure 2C shows that, the effect of N97T or N97D mutations on $\mathrm{HC}-10$ or ME-1 staining shown in figure 1C is not affected by the knockout of ERAP1 in HeLa cells. These results strongly suggest that N97T and N97D mutations do not modulate HLA-B*27 FHC expression through interacting with ERAP1.

As shown in figure 1A, P97 locates at the bottom of the HLA-B*27 peptide-binding groove and might contact $\beta 2 \mathrm{~m}$. Moreover, the adjacent position 96 (P96) has been shown to contact $\beta 2 \mathrm{~m}$ in the crystal structure of HLA-A2.1 and HLA-Aw68.1. ${ }^{5}$ We therefore hypothesized that $\beta 2 \mathrm{~m}$ might be important for the effect of P97 mutation on HLA-B*27 expression. Indeed, in $\beta 2 \mathrm{~m}$ deficient cancer cell line HCT15, no difference in FHC expression between HLA-B*27, HLAB*27-N97T and HLA-B*27-N97D was observed (figure 2D, see online supplementary figure S5D for western blot and flow cytometry confirming the deficiency of $\beta 2 \mathrm{~m}$ ).

\section{Differential surface FHC expression between HLA-B*27, HLA-B*27-N97T and HLA- $B * 27-N 97 D$ is only observed in the presence of $\beta 2 \mathrm{~m}$.}

To confirm the results observed in HCT15 cells, we used CRISPR-Cas9 to generate a $\beta 2 \mathrm{~m}$ knockout HeLa cell line. We found very similar results (ie N97, N97T and N97D heavy chains are expressed at equal levels) (figure $3 \mathrm{~A}$ ). Absence of $\beta 2 \mathrm{~m}$ protein expression in western blot and abolishment of W6/32-reactive molecules on the cell surface confirmed the successful knockout of $\beta 2 \mathrm{~m}$ in HeLa (see online supplementary figure S6). We also found that, in $\beta 2 \mathrm{~m}$ knockout HeLa cells, the effect of N97T or N97D mutation on HLA-B*27 expression was 
restored by transfection of wildtype- $\beta 2 \mathrm{~m}$, but not control plasmid or a $\beta 2 \mathrm{~m}-\mathrm{C} 25 \mathrm{~W}$ loss-offunction mutant (figure 3B). This $\beta 2 \mathrm{~m}$ mutant has been shown to be dysfunctional for HLA class I expression due to misfolding and degradation of $\beta 2 \mathrm{~m} .{ }^{24}$ These results strongly suggest that the differential surface expression observed between HLA-B*27, N97T and N97D mutant is dependent on the presence of functional $\beta 2 \mathrm{~m}$.

\section{P97 amino acid substitutions affect HLA-B*7 and HLA-B*51 expression on the cell surface.}

We lastly examined the effect of P97 residue mutations on the expression of two AS-associated non-B*27 HLA-B alleles. HLA-B*7 is protective against AS, carries Serine (S) at P97 and expresses lower FHC levels than HLA-B*27 (see online supplementary figure S7). Mutation of $\mathrm{S}$ to Asparagine $(\mathrm{N})$, a residue conferring increased risk of AS, significantly increased surface HLA-B*7 FHC expression in both C1R and HeLa cells (figure 4A, B). Mutation of $\mathrm{S}$ to Threonine (T), an AS-predisposing residue, also significantly increased FHC expression in C1R cells (figure 4A). Interestingly, HLA-B*51, which is AS-associated and already carries the AS risk residue Threonine (T) at P97, constitutively expresses FHC at a level as high as that of HLA-B*27 (see online supplementary figure S7). HLA-B*51-T97N further increased the expression of FHC on surface of both C1R and 221 cells (figure 4C, D). As with HLA-B*27, both HLA-B*7 and HLA-B*51 surface expression was significantly reduced by mutation of P97 to Aspartic Acid (D). 


\section{DISCUSSION}

The amino acid present at position 97 (P97) of the HLA-B heavy chain has recently been shown to be a key determinant of the risk of developing Ankylosing Spondylitis (AS). ${ }^{2}$ In the current study we show that the nature of the P97 residue plays a key role in HLA-B*27 free heavy chain (FHC) expression (summarized in online supplementary table S1). Mutation of P97 to the AS risk residue Threonine, but not to the protective residues Serine or Valine, or to the nonassociated residues Arginine or Tryptophan, increased cell surface HLA-B*27 FHC. We also studied two additional HLA-B alleles carrying different P97 residues. For HLA-B*7, weakly AS-protective, and HLA-B*51, weakly AS-predisposing, FHC expression on cell surface was also increased by mutation of the P97 residue to Asparagine $(\mathrm{N})$, a residue conferring the highest risk of disease. Our results thus provide a possible explanation for the genetic association of P97 amino acids and Ankylosing Spondylitis (AS) through altered HLA-B FHC expression.

We also show for the first time that the presence of $\beta 2 \mathrm{~m}$ is essential for the effects of the N97T and N97D mutations on HLA-B*27 expression. Differences in FHC expression between HLA$\mathrm{B} * 27, \mathrm{HLA}-\mathrm{B} * 27-\mathrm{N} 97 \mathrm{~T}$ and HLA-B*27-N97D disappeared in the absence of $\beta 2 \mathrm{~m}$, and were restored by reconstitution of functional $\beta 2 \mathrm{~m}$. One possible mechanism is that P97 alters the strength of association with $\beta 2 \mathrm{~m}$ and therefore influences FHC expression due to subsequent dissociation of HLA class I complexes, either at the cell surface or inside the cells. Considering the similar stability of cell surface classical HLA-B*27 between HLA-B*27, N97T and N97D mutants, P97 likely affects maturation or trafficking of HLA-B*27 inside cells. The N97D mutant reduced the rate in recovery of cell surface HLA-B*27 FHCs and classical complexes, whereas N97T promoted the recovery of cell surface FHCs without affecting classical complexes. 
One possible explanation is that HLA-B*27-N97D heavy chains have such poor affinity for $\beta 2 \mathrm{~m}$ that they rarely pass the quality control in the ER, resulting in low expression levels of both classical complexes and FHCs on the cell surface. By contrast, HLA-B*27-N97T heavy chains likely have weak but sufficient association with $\beta 2 \mathrm{~m}$ to allow complexes to exit the ER, but subsequently dissociate during trafficking to the cell surface leading to elevated FHC on the cell surface. Such a model is shown in cartoon form in figure 5. The hierarchy of HLA-B*27, N97T and N97D in affinity with $\beta 2 \mathrm{~m}$ is supported by our finding that levels of intracellular HLA-B*27 FHCs were highest for the N97D mutant, followed by N97T, and then wild type HLA-B*27.

Notably, mutation of P97 to the protective residues ( $\mathrm{S}$ and V) did not significantly reduce the expression level of HLA-B*27 FHC on the cell surface (figure 1B, C). One explanation is that the effect of this mutation has been overrided by other inherent features of HLA-B*27 that contribute to its high level of FHC expression. Indeed, formation of HLA-B $* 27$ heavy chain homodimers through cysteine at position 67 and its slow folding kinetics have both been implicated in the generation of HLA-B*27 FHCs. ${ }^{18} 192526$

In addition to HLA-B*27, cell surface expression of HLA-B*7 and HLA-B*51 was also affected by residue variations at P97, suggesting that this may be a more general phenomenon for HLA-B allotypes. However, the effects of different P97 residues may occur in an allotype-specific context. Indeed, the different levels of FHC expression seen between 97N and 97S in HLA-B*7 were not observed in HLA-B*27. Moreover, the mutation of $\mathrm{T}$ to $\mathrm{N}$ increased FHC expression for HLA-B*51 whereas reverse effect was seen for HLA-B*27. 
Of note, cell surface expression levels of classical HLA-B*27 molecules were relatively little affected by the N97T mutation in all cell lines studied, apart from the increase in TAP-deficient T2 cells. The observation that N97D nearly abolishes ME-1 staining in T2 cells suggests that TAP does not interact with amino acids at P97. One possible explanation is that the available peptide pool in the ER of TAP-deficiency T2 cells happens to have higher affinity with the N97T mutant than with HLA-B*27 FHC.

The molecular basis for the association of HLA-B27 with AS remains mysterious. A key pathogenic role for P97 of HLA-B has recently been reported. ${ }^{2}$ Our data suggest that a possible functional explanation for this observation lies in the effect of this residue on the assembly of HLA-B with $\beta 2 \mathrm{~m}$. Further detailed biochemical study of these results needs to be carried out to understand the mechanism leading to differential FHC expression at the cell surface.

Overall, our data show that the P97 residue substantially influences expression levels of HLAB*27 free heavy chains. The association of P97 amino acid polymorphisms with AS could therefore, at least in part, be explained by its significant effects on HLA-B free heavy chain cell surface expression.

\section{Acknowledgements}

We sincerely thank Arthritis Research UK (20235, LC\&HS), Oxford NIHR Biomedical Research Unit (PB) for funding. We thank Dr Yanchun Peng and Professor Tao Dong, Weatherall Institute of Molecular Medicine, Oxford for HLA-B*51:01 lentiviral plasmid, and Professor Hidde L. Ploegh, Whitehead Institute, Mass USA for HC-10 antibody. We also thank 
Dr Adrian Cortes, Wellcome Trust, Oxford and Dr Ariane Hammitzsch, Nuffield Department of Orthopaedics, Rheumatology and Musculoskeletal Sciences, Oxford for comments on the manuscript. 


\section{REFERENCES}

1. Evans DM, Spencer CC, Pointon JJ, et al. Interaction between ERAP1 and HLA-B27 in ankylosing spondylitis implicates peptide handling in the mechanism for HLA-B27 in disease susceptibility. Nat Genet 2011;43(8):761-7

2. Cortes A, Pulit SL, Leo PJ, et al. Major histocompatibility complex associations of ankylosing spondylitis are complex and involve further epistasis with ERAP1. Nat Commun 2015;6

3. Madden DR, Gorga JC, Strominger JL, Wiley DC. The three-dimensional structure of HLAB27 at 2.1 A resolution suggests a general mechanism for tight peptide binding to MHC. Cell 1992;70(6):1035-48

4. Stewart-Jones GB, di Gleria K, Kollnberger S, McMichael AJ, Jones EY, Bowness P. Crystal structures and KIR3DL1 recognition of three immunodominant viral peptides complexed to HLA-B*2705. Eur J Immunol 2005;35(2):341-51

5. Tysoe-Calnon VA, Grundy JE, Perkins SJ. Molecular comparisons of the beta 2microglobulin-binding site in class I major-histocompatibility-complex alpha-chains and proteins of related sequences. Biochem J 1991;277 ( Pt 2):359-69

6. Blanco-Gelaz MA, Suarez-Alvarez B, Gonzalez S, Lopez-Vazquez A, Martinez-Borra J, Lopez-Larrea C. The amino acid at position 97 is involved in folding and surface expression of HLA-B27. International immunology 2006;18(1):211-20

7. Taurog JD, Dorris ML, Satumtira N, et al. Spondylarthritis in HLA-B27/human beta2microglobulin-transgenic rats is not prevented by lack of CD8. Arthritis Rheum 2009;60(7):1977-84 
8. May E, Dorris ML, Satumtira N, et al. CD8 alpha beta $\mathrm{T}$ cells are not essential to the pathogenesis of arthritis or colitis in HLA-B27 transgenic rats. $\mathbf{J}$ Immunol 2003;170(2):1099-105

9. Kollnberger S, Bird L, Sun MY, et al. Cell-surface expression and immune receptor recognition of HLA-B27 homodimers. Arthritis Rheum 2002;46(11):2972-82

10. Tsai WC, Chen CJ, Yen JH, et al. Free HLA class I heavy chain-carrying monocytes--a potential role in the pathogenesis of spondyloarthropathies. J Rheumatol 2002;29(5):966-72

11. Raine T, Brown D, Bowness P, et al. Consistent patterns of expression of HLA class I free heavy chains in healthy individuals and raised expression in spondyloarthropathy patients point to physiological and pathological roles. Rheumatology (Oxford) 2006;45(11):1338-44

12. DeLay ML, Turner MJ, Klenk EI, Smith JA, Sowders DP, Colbert RA. HLA - B27 misfolding and the unfolded protein response augment interleukin - 23 production and are associated with Th17 activation in transgenic rats. Arthritis \& Rheumatism 2009;60(9):2633-43

13. Guiliano DB, Fussell H, Lenart I, et al. Endoplasmic reticulum degradation-enhancing alphamannosidase-like protein 1 targets misfolded HLA-B27 dimers for endoplasmic reticulumassociated degradation. Arthritis Rheumatol 2014;66(11):2976-88

14. Bowness P, Ridley A, Shaw J, et al. Th17 cells expressing KIR3DL2+ and responsive to HLA-B27 homodimers are increased in ankylosing spondylitis. $\mathbf{J}$ Immunol 2011;186(4):2672-80

15. Payeli SK, Kollnberger S, Osiris Marroquin B, et al. Inhibiting HLA-B27 homodimer-driven immune cell inflammation in spondyloarthritis. Arthritis Rheum 2012 
16. Kollnberger S, Bowness P. The role of B27 heavy chain dimer immune receptor interactions in spondyloarthritis. Advances in experimental medicine and biology 2009;649:277-85

17. Cauli A, Shaw J, Giles J, et al. The arthritis-associated HLA-B*27:05 allele forms more cell surface B27 dimer and free heavy chain ligands for KIR3DL2 than HLA-B*27:09. Rheumatology (Oxford) 2013;52(11):1952-62

18. Bird LA, Peh CA, Kollnberger S, Elliott T, McMichael AJ, Bowness P. Lymphoblastoid cells express HLA-B27 homodimers both intracellularly and at the cell surface following endosomal recycling. Eur J Immunol 2003;33(3):748-59

19. Allen RL, O'Callaghan CA, McMichael AJ, Bowness P. Cutting edge: HLA-B27 can form a novel beta 2-microglobulin-free heavy chain homodimer structure. $\mathrm{J}$ Immunol 1999;162(9):5045-8

20. Rein RS, Seemann GH, Neefjes JJ, Hochstenbach FM, Stam NJ, Ploegh HL. Association with beta 2-microglobulin controls the expression of transfected human class I genes. J Immunol 1987;138(4):1178-83

21. Ran FA, Hsu PD, Wright J, Agarwala V, Scott DA, Zhang F. Genome engineering using the CRISPR-Cas9 system. Nature protocols 2013;8(11):2281-308

22. Wearsch PA, Cresswell P. The quality control of MHC class I peptide loading. Curr Opin Cell Biol 2008;20(6):624-31

23. Chen L, Ridley A, Hammitzsch A, et al. Silencing or inhibition of endoplasmic reticulum aminopeptidase 1 (ERAP1) suppresses free heavy chain expression and Th17 responses in ankylosing spondylitis. Ann Rheum Dis 2015 
24. Chang CC, Ogino T, Mullins DW, et al. Defective human leukocyte antigen class Iassociated antigen presentation caused by a novel beta2-microglobulin loss-of-function in melanoma cells. J Biol Chem 2006;281(27):18763-73

25. Bowness P. HLA B27 in health and disease: a double-edged sword? Rheumatology (Oxford) 2002;41(8):857-68

26. Antoniou AN, Ford S, Taurog JD, Butcher GW, Powis SJ. Formation of HLA-B27 homodimers and their relationship to assembly kinetics. J Biol Chem 2004;279(10):8895902 


\section{FIGURE LEGENDS}

Figure 1 Location of P97 in HLA-B*27 crystal structure and effects of P97 residue substitutions on HLA-B*27 cell surface expression. Location of P97 in HLA-B*27 structure is shown in side and bottom views (A). C1R (B) or HeLa (C) cells were transduced using lentiviruses to express equal amounts of HLA-B*27 (N97) and six mutants at position 97 (N97T, N97S, N97V, N97R, N97W and N97D). HLA-B*27 free heavy chain (HC-10 antibody) and classical HLA-B*27 complex (ME-1 antibody) cell surface expression is shown. Results are expressed as mean and standard deviation. $\mathrm{P}$ value was determined using unpaired two-tailed $\mathrm{t}$ test $(* *=\mathrm{P}<0.01, * * *=\mathrm{p}<0.001)$. All experiments were repeated three times.

Figure 2 Differences in free heavy chain expression levels between HLA-B*27, HLA$B * 27-N 97$ T and HLA-B*27-N97D disappear in the absence of $\beta 2 \mathrm{~m}$, but not TAP, tapasin or ERAP1. TAP-deficient T2 cells (A), tapasin-deficient 220 cells (B), ERAP1-CRISPR-knockout HeLa cells (C) and $\beta 2 \mathrm{~m}$-deficient HCT15 cells (D) were transduced using lentiviruses to express HLA-B*27(N97), HLA-B*27-N97T and HLA-B*27-N97D mutants. HLA-B*27 free heavy chain (HC-10 antibody) and classical HLA-B*27 complex (ME-1 antibody) cell surface expression is shown. Representative results are shown as FACS plot. All experiments were repeated three times.

Figure 3 Differential expression between HLA-B*27, HLA-B*27-N97T and HLA-B*27N97D is only observed in the presence of $\beta 2 \mathrm{~m}$. $\beta 2 \mathrm{~m}$-CRISPR-knockout HeLa cells (A) were transduced using lentiviruses to express HLA-B*27(N97), HLA-B*27-N97T and HLA-B*27N97D mutants. $\beta 2 \mathrm{~m}$-knockout HeLa cells were co-transfected with HLA-B*27/HLA-B*27- 
N97T/HLA-B*27-N97D DNA plasmid and $\beta 2 \mathrm{~m} /$ loss-of-function $\beta 2 \mathrm{~m}-\mathrm{C} 25 \mathrm{~W}$ mutant DNA plasmid (B). HLA-B*27 free heavy chain (HC-10 antibody) and classical HLA-B*27 complex (ME-1 antibody) cell surface expression is shown. Representative results are shown as FACS plots (A) or expressed as mean and standard deviation (B). P value was determined using unpaired two-tailed t-test $(* *=\mathrm{P}<0.01, * * *=\mathrm{p}<0.001)$. All experiments were repeated three times.

Figure 4 P97 amino acids affect HLA-B*7 and HLA-B*51 expression on the cell surface. C1R (A) or HeLa (B) cells were transduced using lentiviruses to express HLA-B*7 (S97) and three mutants at position 97 (S97N, S97T and S97D). HLA-B*51 (T97) and its mutants at position 97 (T97N and T97D) were also stably expressed in C1R (C) or 221 (D) cells. HLA-B*7 and HLA-B*51 free heavy chain (HC-10 antibody), classical HLA-B*7 complex (ME-1 antibody) and classical HLA-B*51 complex cell surface expression is shown. Results are expressed as mean and standard deviation. $\mathrm{P}$ value was determined using unpaired two-tailed $\mathrm{t}$ test $(*=\mathrm{P}<0.05, * *=\mathrm{P}<0.01, * * *=\mathrm{p}<0.001)$. All experiments were repeated three times.

Figure 5 Cartoon showing possible effects of N97T and N97D mutation on HLA-B*27 assembly and cell surface expression. HLA-B*27-N97D heavy chains have such poor affinity for $\beta 2 \mathrm{~m}$ that they rarely pass the quality control in the ER, resulting in low expression levels of both classical complexes and FHCs on the cell surface. By contrast, HLA-B*27-N97T heavy chains likely have weak but sufficient association with $\beta 2 \mathrm{~m}$ to allow complexes to exit the ER, but subsequently dissociate during trafficking to the cell surface leading to elevated FHC on the cell surface. 
Table 1 Association of P97 residues of HLA-B with AS

\begin{tabular}{ccccc}
\hline $\begin{array}{c}\text { P97 } \\
\text { residues }\end{array}$ & Association with AS & $\begin{array}{c}{ }^{*} \text { Odds } \\
\text { ratio }\end{array}$ & $\begin{array}{c}{ }^{*} \mathrm{P} \\
\text { value }\end{array}$ & $\begin{array}{c}\text { Examples of HLA- } \\
\text { B allele }\end{array}$ \\
\hline $\mathrm{N}$ & Risk & 16.51 & $<10^{-300}$ & $* 27: 05$ \\
$\mathrm{~T}$ & Risk & 1.12 & $4.5 \times 10^{-3}$ & $* 51: 01$ \\
& & & & $* 13: 02$ \\
$\mathrm{R}$ & Non-associated & 1 & 1 & $* 15: 01$ \\
& & & & $* 40: 01$ \\
$\mathrm{~W}$ & Non-associated & 1 & 0.95 & $* 47: 01$ \\
$\mathrm{~S}$ & Protective & 0.86 & $4.81 \times 10^{-8}$ & $* 07: 02$ \\
& & & & $* 40: 02$ \\
$\mathrm{~V}$ & Protective & 0.68 & $1.41 \times 10^{-8}$ & $* 57: 01$ \\
$\mathrm{D}$ & Synthetic & $\mathrm{N} / \mathrm{A}$ & $\mathrm{N} / \mathrm{A}$ & $\mathrm{N} / \mathrm{A}$ \\
\hline
\end{tabular}

* Statistics from Cortes A. et al. Nat Commun, 2015, Fisher's exact test used for $\mathbf{P}$ value. The HLA-B allotypes investigated in current study, HLA-B*27:05, HLA-B*51:01 and HLA-B*07:01, are highlighted in bold. Of note, Aspartic acid (D) is not present in P97 of HLA-B. 

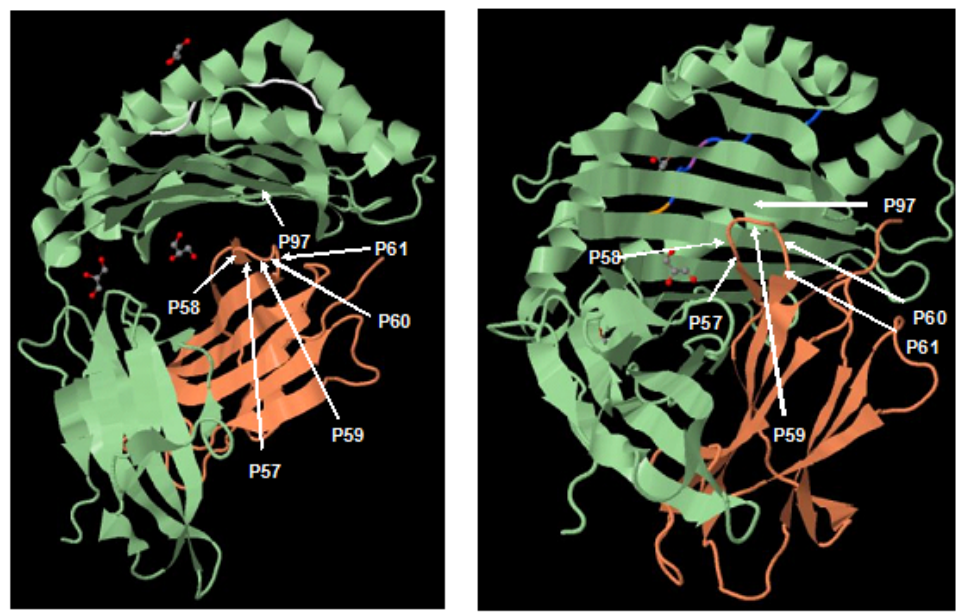

Green: HLA-B*27 heavy

chain

Red: $\beta 2 \mathrm{~m}$

B

C1R transfectants $\mathrm{HC}-10$
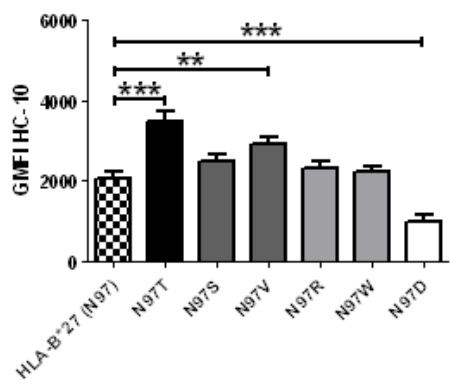

C
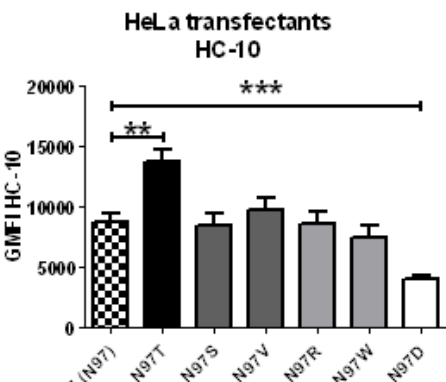

C1R transfectants ME-1

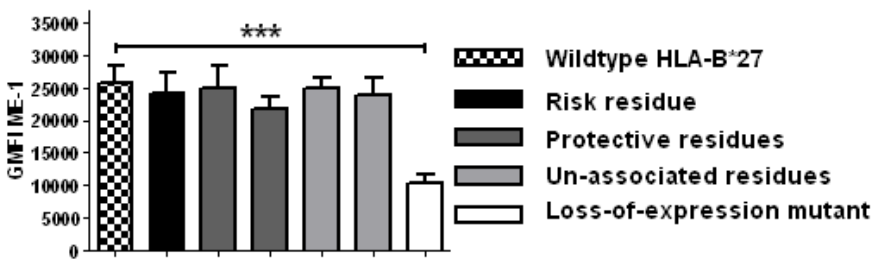

HeL a transfectants

ME-1

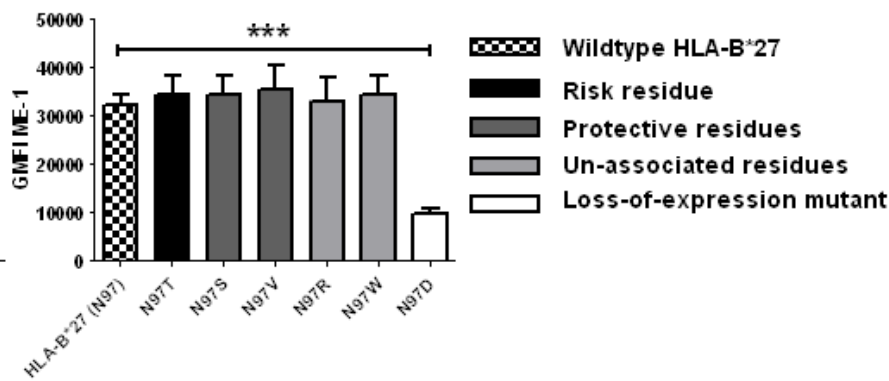

Figure 1 Location of P97 in HLA-B*27 crystal structure and effects of P97 residue substitutions on HLA-B*27 cell surface expression. Location of P97 in HLA-B*27 structure is shown in side and bottom views (A). C1R (B) or HeLa (C) cells were transduced using lentiviruses to express equal amounts of HLA-B*27 (N97) and six mutants at position 97 (N97T, N97S, N97V, N97R, N97W and N97D). HLA-B*27 free heavy chain (HC-10 antibody) and classical HLA-B*27 complex (ME-1 antibody) cell surface expression is shown. Results are expressed as mean and standard deviation. $P$ value was determined using unpaired two-tailed t-test $(* *=\mathrm{P}<0.01, * * *=\mathrm{p}<0.001)$. All experiments were repeated three times. 


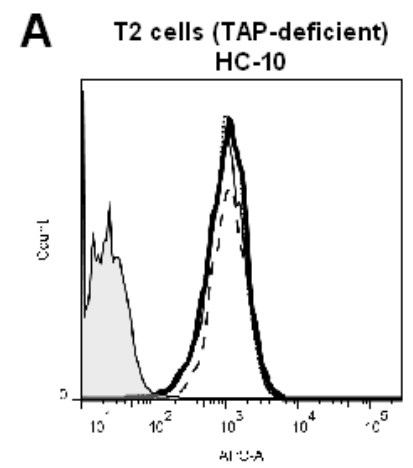

B 220 cells (Tapasin-deficient) HC-10

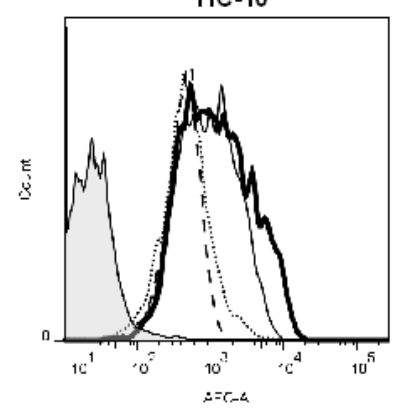

C ERAP1-KO HeLa cells HC-10

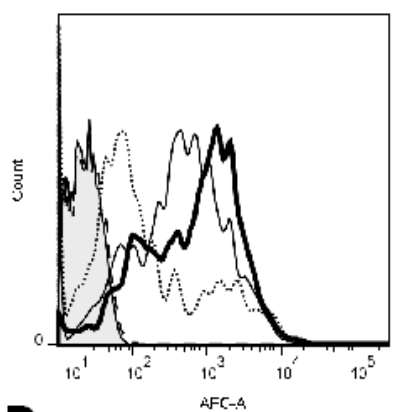

D HCT15 cells ( $\beta 2 m$-deficient)

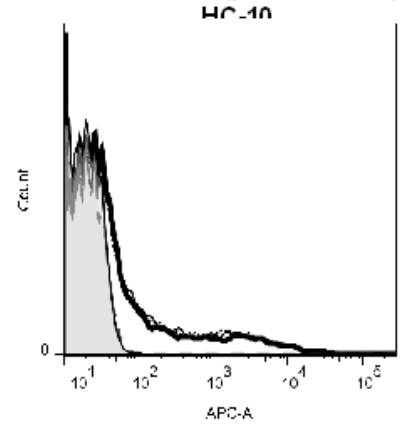

T2 cells (TAP-deficient) ME-1

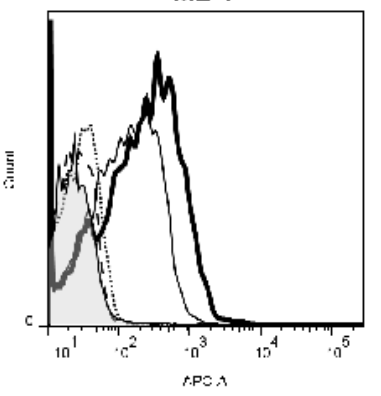

220 cells (Tapasin-deficient) ME-1

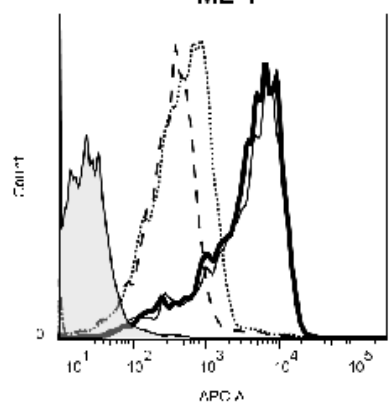

ERAP1-KO HeLa cells ME-1

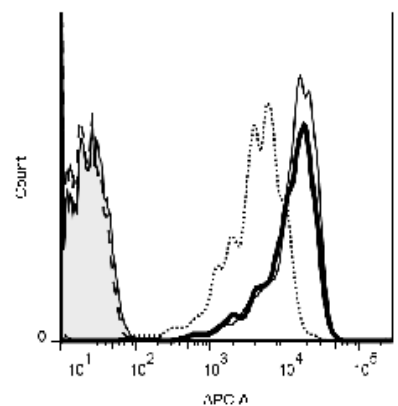

HCT15 cells ( $\beta 2 \mathrm{~m}$-deficient) MF-1

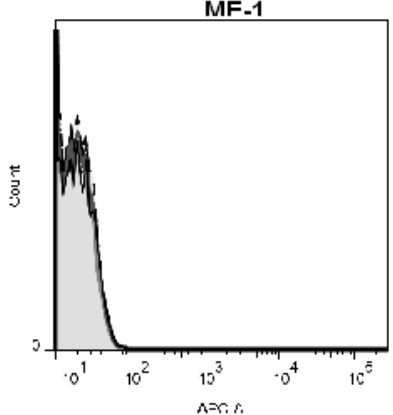

Dashed: Untransfected T2

Solid: T2.B*27

Solid\&heavy: T2.B*27-N97T

Dotted: T2.B*27-N97D

Tinted: Isotype control

Dashed: Untransfected 220

Solid: $220 . B^{*} 27$

Solid\&heavy: 220 .B $27-$ N97T

Dotted: 220.B*27-N97D

Tinted: Isotype control

Dashed: Untransfected HeLa.ERAP1-KO

Solid: HeLa.ERAP1-K0.B*27

Solid\&heavy: HeLa.ERAP1-K0.B*27-N97T

Dotted: HeLa.ERAP1-K0.B`27-N97D

Tinted: Isotype control

Dashed:Untransfected HCT15

Solid: HCT15.B*27

Solid\&heavy: HCT15.B*27-N97T

Dotted: HCT15.B²7-N97D

Tinted: Isotype control

Figure 2 Differences in free heavy chain expression levels between HLA-B*27, HLA-B*27N97T and HLA-B*27-N97D disappear in the absence of $\beta 2 \mathrm{~m}$, but not TAP, tapasin or ERAP1. TAPdeficient T2 cells (A), tapasin-deficient 220 cells (B), ERAP1-CRISPR-knockout HeLa cells (C) and $\beta 2 m$-deficient HCT15 cells (D) were transduced using lentiviruses to express HLA-B*27(N97), HLA-B*27-N97T and HLA-B*27-N97D mutants. HLA-B*27 free heavy chain (HC-10 antibody) and classical HLA-B*27 complex (ME-1 antibody) cell surface expression is shown. Representative results are shown as FACS plot. All experiments were repeated three times. 
A

ß2m-KO HeLa cells

HC-10

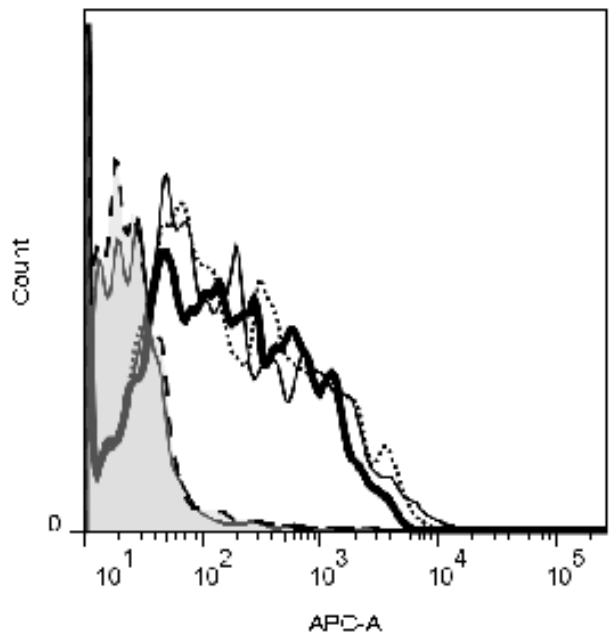

B

$\beta 2 m-K O$ HeLa transfectants HC-10

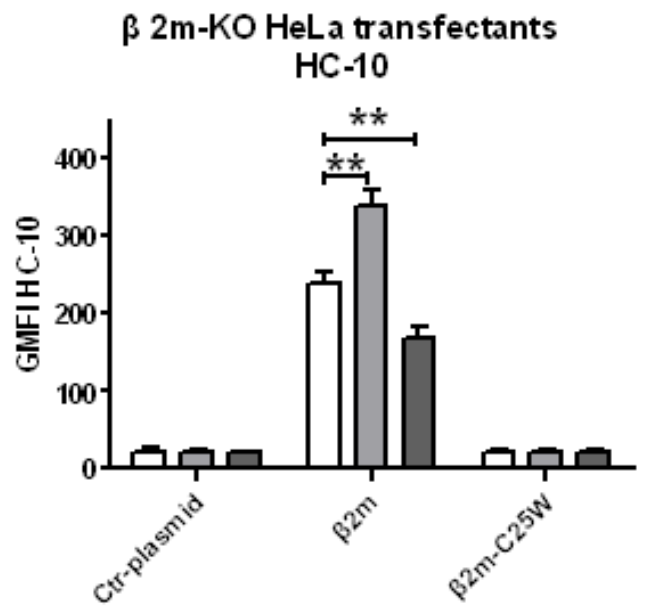

ß2m-KO HeLa cells

ME-1

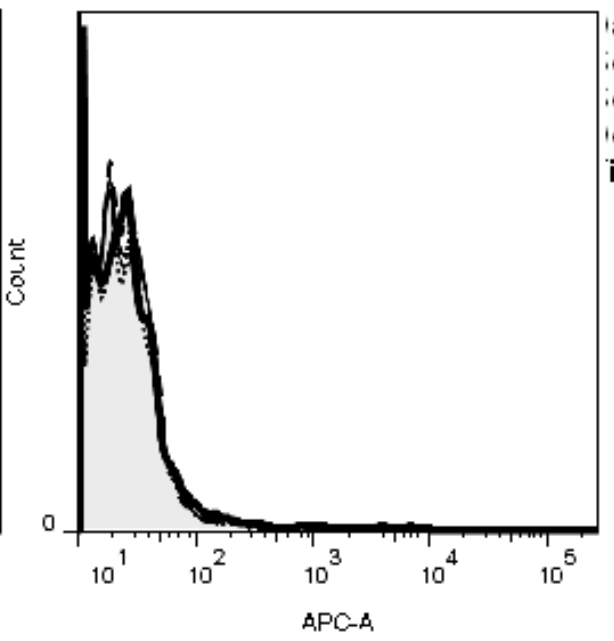

ashed: Untransfected HeLa. $\beta 2 \mathrm{~m}-\mathrm{KO}$ olid: HeLa.ß2m-KO.B*27 olid\&heavy: HeLa.\$2m-K0.B*27-N97T otted: HeLa.ß2m-K0.B²7-N97D inted: Isotype control

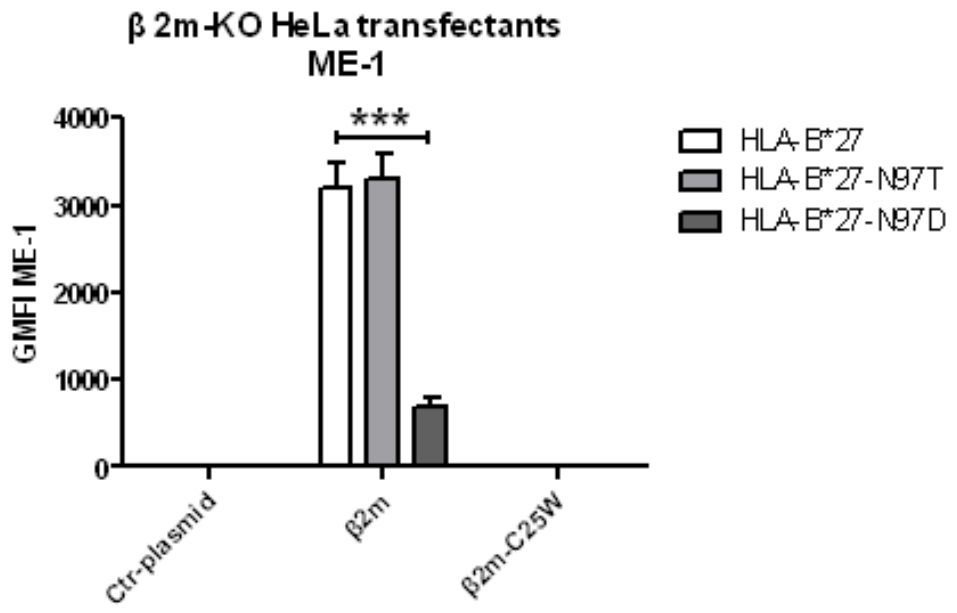

Figure 3 Differential expression between HLA-B*27, HLA-B*27-N97T and HLA-B*27N97D is only observed in the presence of $\beta 2 \mathrm{~m}$. $\beta 2 \mathrm{~m}$-CRISPR-knockout HeLa cells $(A)$ were transduced using lentiviruses to express HLA-B*27(N97), HLA-B*27-N97T and HLA-B*27N97D mutants. $\beta 2 m$-knockout HeLa cells were co-transfected with HLA-B*27/HLA-B*27N97T/HLA-B*27-N97D DNA plasmid and $\beta 2 \mathrm{~m} /$ loss-of-function $\beta 2 \mathrm{~m}-\mathrm{C} 25 \mathrm{~W}$ mutant DNA plasmid (B). HLA-B*27 free heavy chain (HC-10 antibody) and classical HLA-B*27 complex (ME-1 antibody) cell surface expression is shown. Representative results are shown as FACS plots (A) or expressed as mean and standard deviation (B). P value was determined using unpaired two-tailed t-test $(* *=\mathrm{P}<0.01, * * *=\mathrm{p}<0.001)$. All experiments were repeated three times. 
A

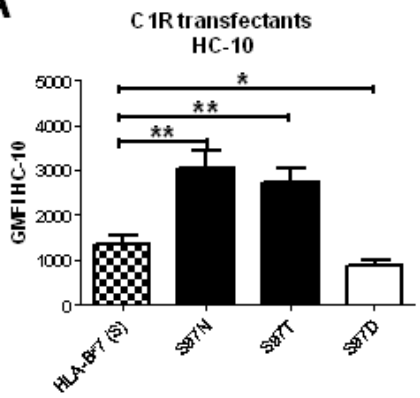

B

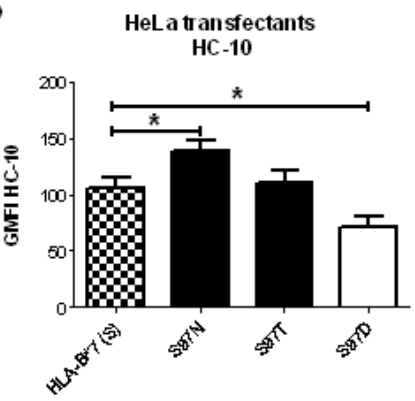

C

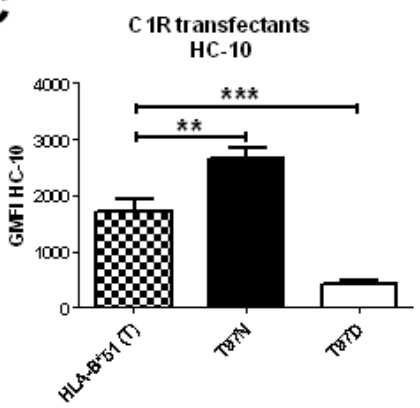

D

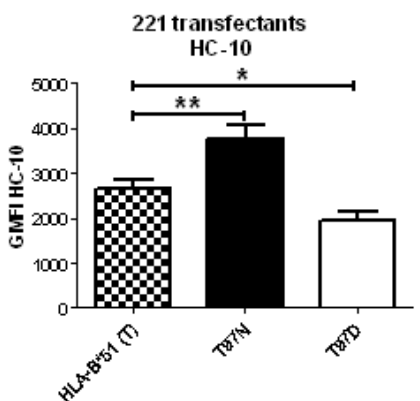

C 1R transfectants ME-1

Won Wildtype HLA-B 7

Risk residues

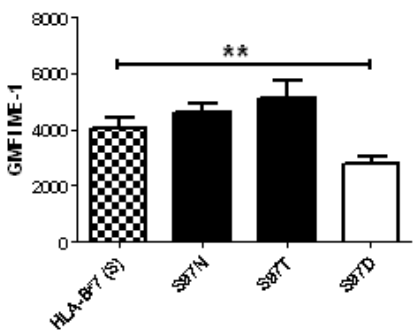

$\square$ Loss-of-expression mutant
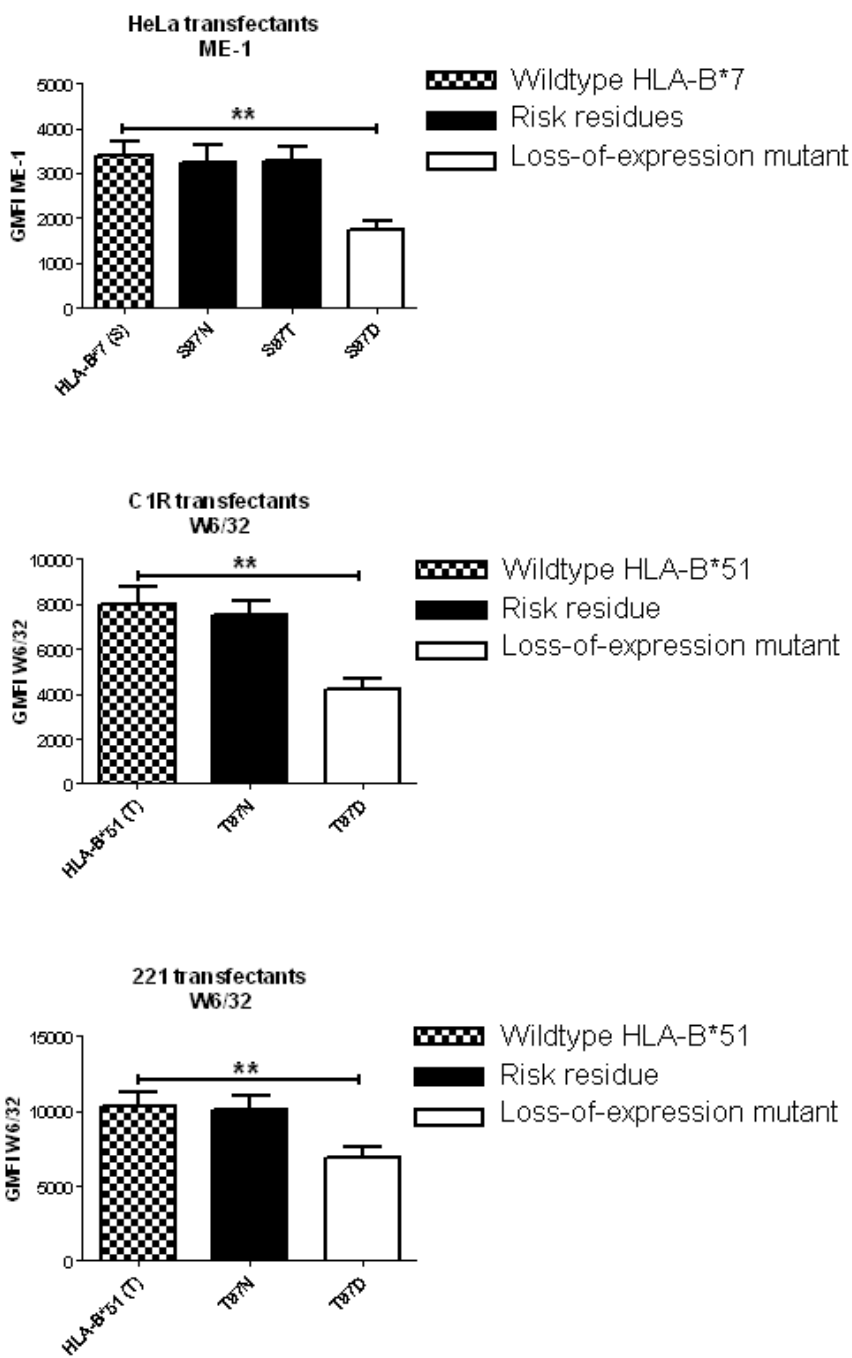

Figure 4 P97 amino acids affect HLA-B*7 and HLA-B*51 expression on the cell surface. C1R (A) or HeLa (B) cells were transduced using lentiviruses to express HLA-B*7 (S97) and three mutants at position 97 (S97N, S97T and S97D). HLA-B*51 (T97) and its mutants at position 97 (T97N and T97D) were also stably expressed in C1R (C) or 221 (D) cells. HLA-B*7 and HLA-B*51 free heavy chain (HC-10 antibody), classical HLA-B*7 complex (ME-1 antibody) and classical HLA-B*51 complex cell surface expression is shown. Results are expressed as mean and standard deviation. $P$ value was determined using unpaired twotailed t-test $(*=\mathrm{P}<0.05, * *=\mathrm{P}<0.01, * * *=\mathrm{p}<0.001)$. All experiments were repeated three times. 


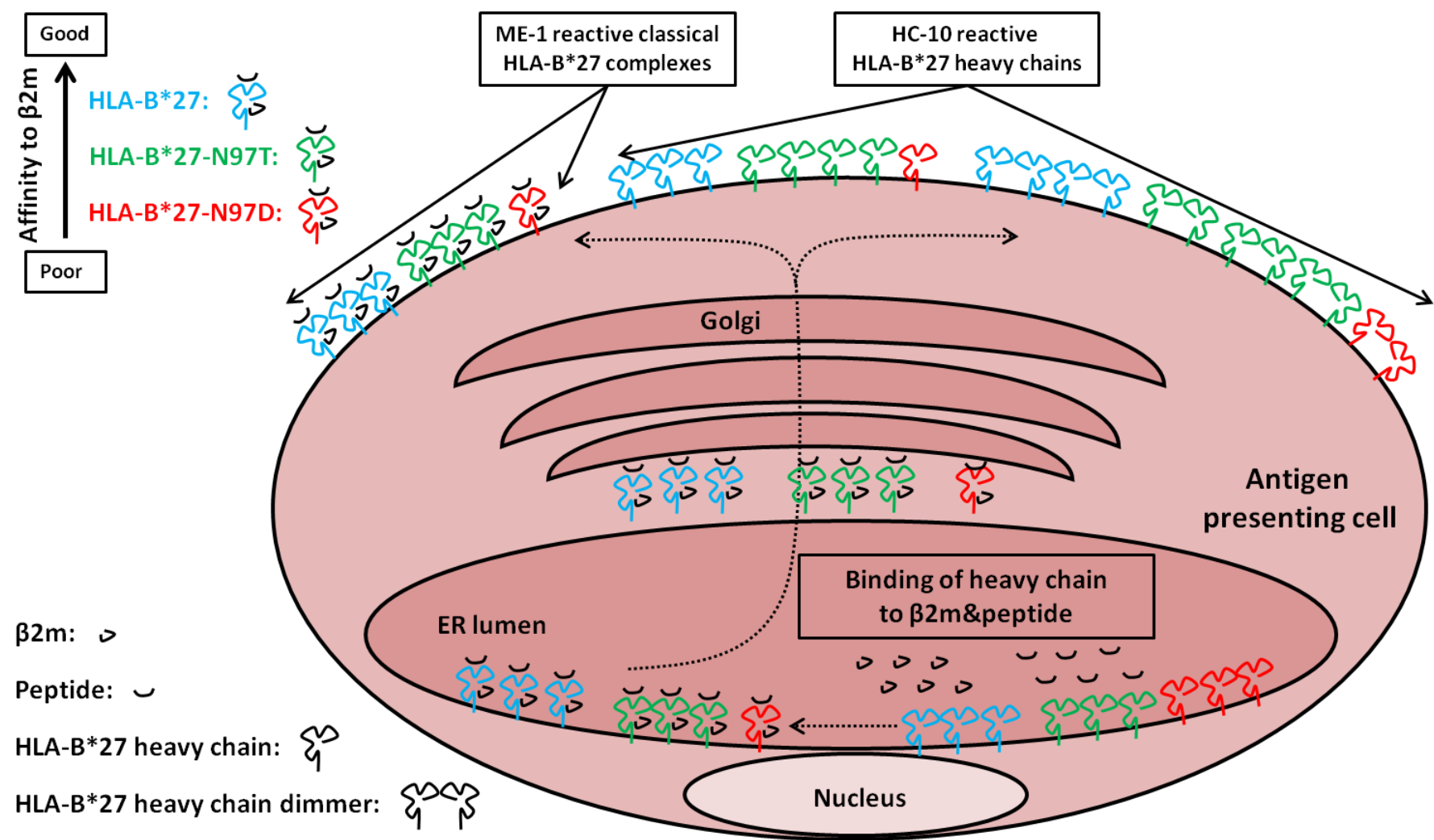

Figure 5 Cartoon showing possible effects of N97T and N97D mutation on HLA-B*27 assembly and cell surface expression. HLA-B*27-N97D heavy chains have such poor affinity for $\beta 2 \mathrm{~m}$ that they rarely pass the quality control in the ER, resulting in low expression levels of both classical complexes and FHCs on the cell surface. By contrast, HLA-B*27-N97T heavy chains likely have weak but sufficient association with $\beta 2 \mathrm{~m}$ to allow complexes to exit the $\mathrm{ER}$, but subsequently dissociate during trafficking to the cell surface leading to elevated FHC on the cell surface. 
Table S1 Summary of the effects of P97 residues on HLA-B*27, HLA-B*51 and HLA-B*7 free heavy chain (FHC) expression studied in this paper

\begin{tabular}{|c|c|c|c|c|c|}
\hline $\begin{array}{l}\text { HLA-B alleles } \\
\text { studied }\end{array}$ & $\begin{array}{l}\text { Association } \\
\text { with AS }\end{array}$ & $\begin{array}{l}\text { Baseline } \\
\text { FHC }\end{array}$ & $\begin{array}{l}\text { Mutations of } \\
\text { P97 residue }\end{array}$ & $\begin{array}{l}\text { Association of } \\
\text { residues with AS }\end{array}$ & $\begin{array}{c}\text { Change of } \\
\text { FHC }\end{array}$ \\
\hline \multirow[t]{5}{*}{ HLA-B*27 (N) } & Risk & High & $\mathrm{T}$ & Risk & Increase \\
\hline & & & $\mathrm{S}$ & Protective & No effect \\
\hline & & & V & Protective & $\begin{array}{c}\text { Mild increase in } \\
\text { C1R cells, no effect } \\
\text { in HeLa cells }\end{array}$ \\
\hline & & & $\mathrm{R}$ & Non-associated & No effect \\
\hline & & & W & Non-associated & No effect \\
\hline HLA-B*51 (T) & Risk & High & $\mathrm{N}$ & Risk & Increase \\
\hline \multirow[t]{2}{*}{ HLA-B*7 (S) } & Protective & Low & $\mathrm{N}$ & Risk & Increase \\
\hline & & & $\mathrm{T}$ & Risk & $\begin{array}{c}\text { Increase in } \\
\text { C1R cells, no effect } \\
\text { in HeLa cells }\end{array}$ \\
\hline
\end{tabular}



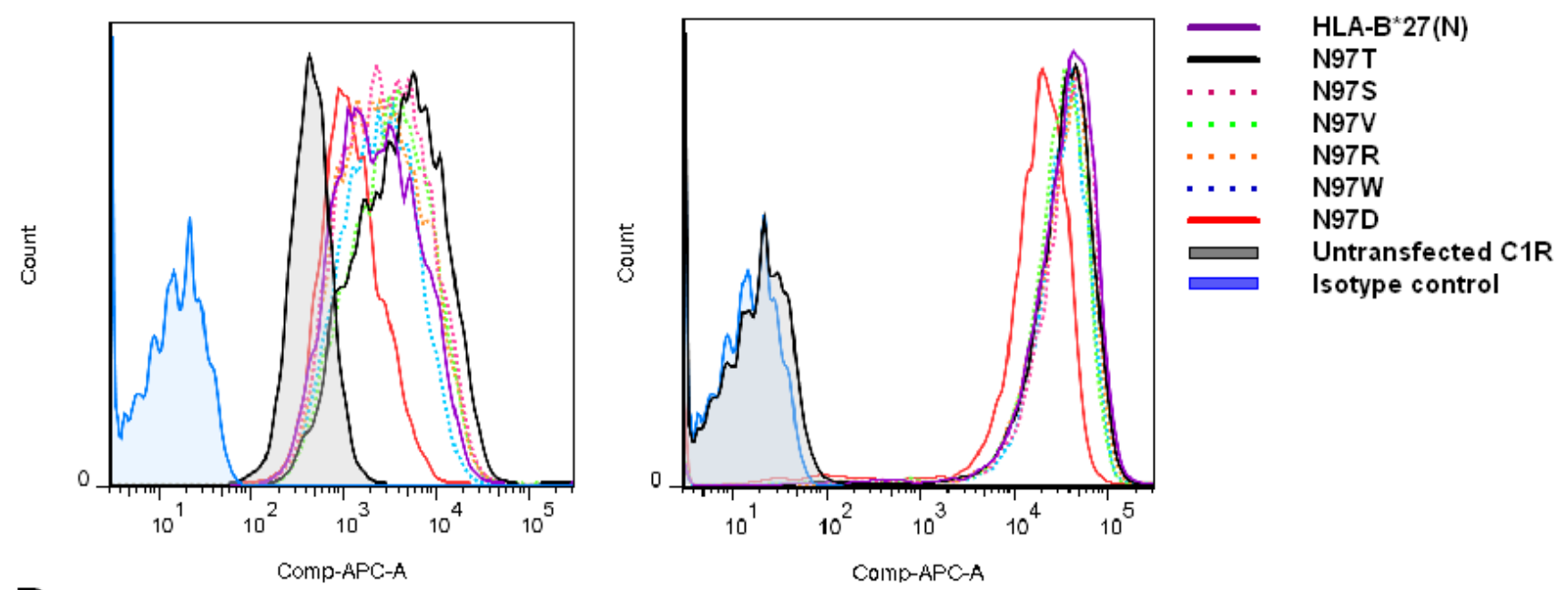

B

HeLa transfectants HC-10

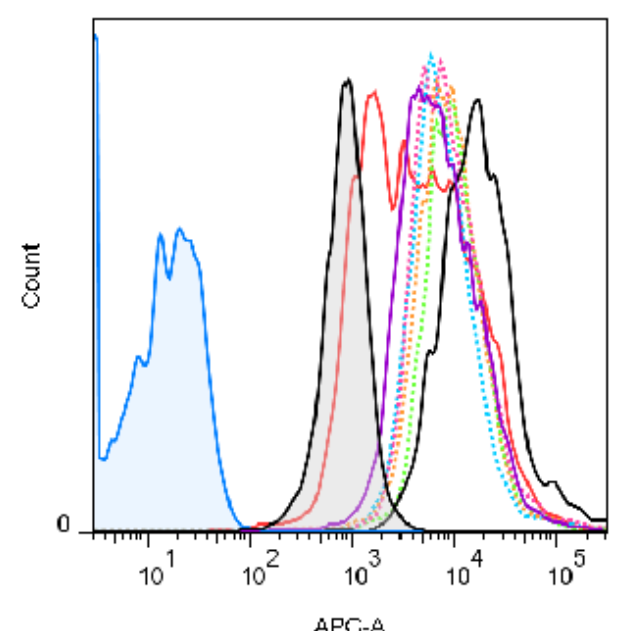

\section{HeLa transfectants}

ME-1

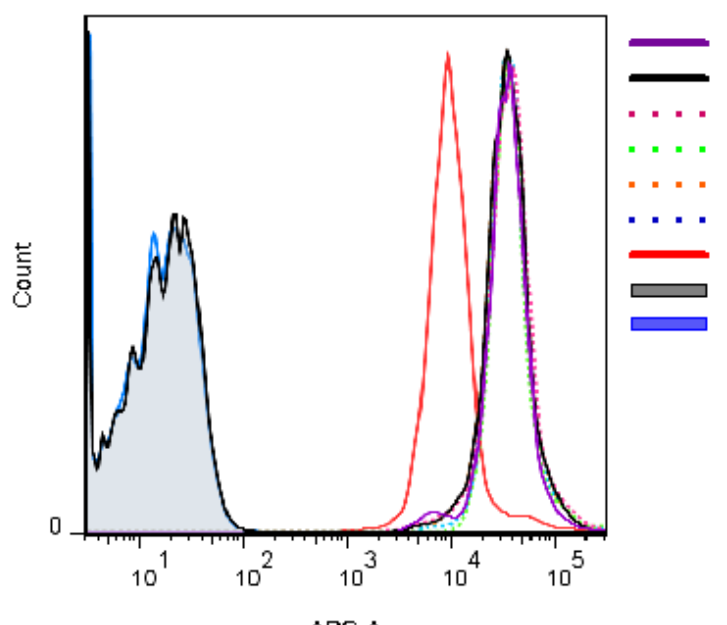

\section{HLA-B ${ }^{\star 27}(\mathrm{~N})$}

N97T

N97S

N97V

N97R

N97W

N97D

Untransfected HeLa

Isotype control

Figure S1 P97 amino acids affect HLA-B*27:05 expression on the cell surface. C1R or HeLa cells were transfected using lentivirus to express HLA-B*27(N) and six mutants at position 97 (N97T, N97S, N97V, N97R, N97W and N97D). HLA-B*27 free heavy chains (HC-10 antibody) and classical HLA-B*27 complexes (ME-1 antibody) cell surface expression by C1R transfectants (A) and HeLa transfectants (B) are shown. Representative of $N=3$ experiments. 
A

\section{HLA-B*27 stability in C1R transfectants}

(ME-1)

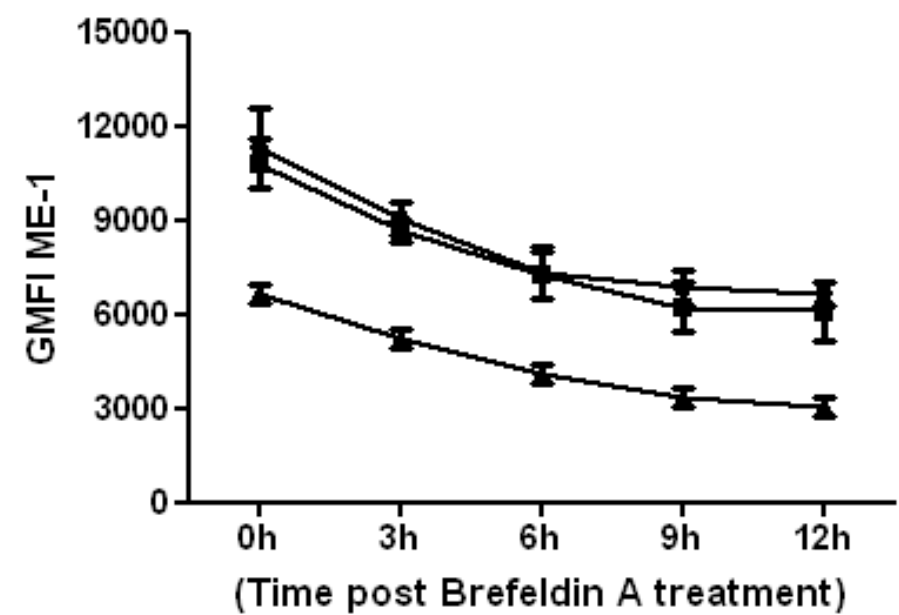

B

\section{HLA-B*27 stability in HeLa transfectants}

(ME-1)

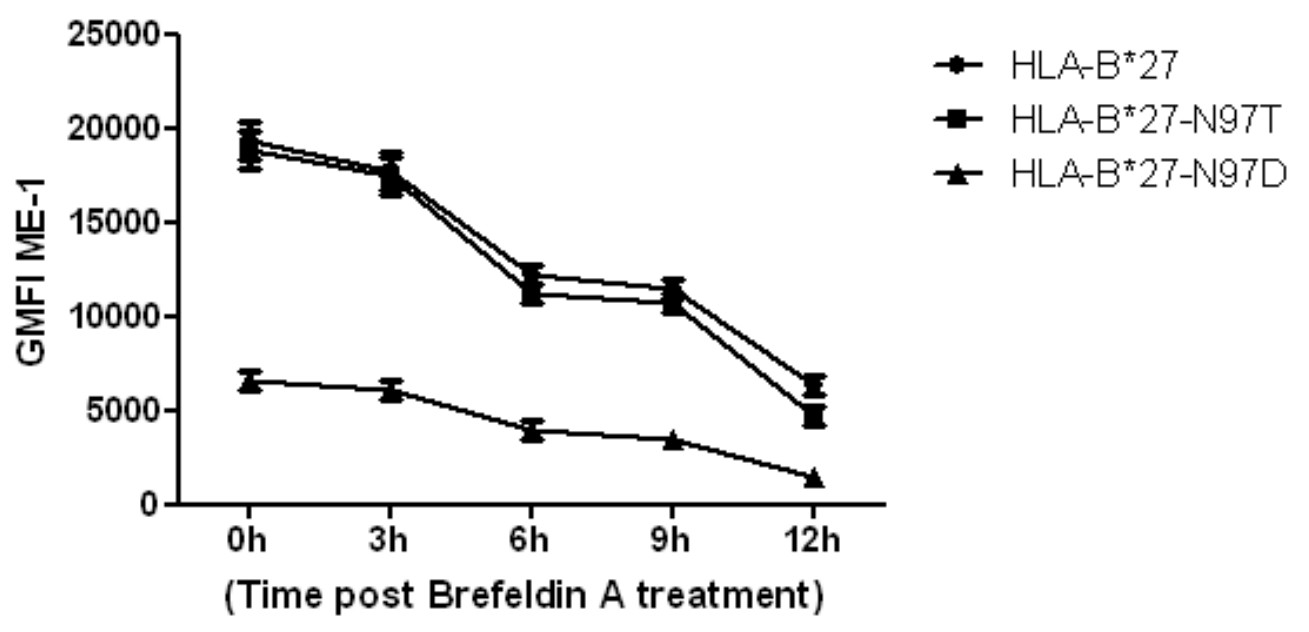

Figure S2. Similar stability of cell surface classical complexes between HLA-B*27, HLA-B*7 and HLA-B*51. C1R (A) or HeLa (B) cells expressing HLA-B*27 (N97), N97T or N97D mutants were treated with $6 \mu \mathrm{g} / \mathrm{ml}$ of Brefeldin A to stop egress of classical HLA-B*27 complexes to cell surface. Cell were then stained using ME-1 for cell surface HLA-B*27 classical complexes at different time points ( $0 \mathrm{~h}, 3 \mathrm{~h}, 6 \mathrm{~h}, 9 \mathrm{~h}$ and $12 \mathrm{~h}$ ). The experiment was repeated three times, representative results are shown as mean and standard deviation. 
$H L A-B^{\star} 27$ recovery in C1R transfectants $(\mathrm{HC}-10)$

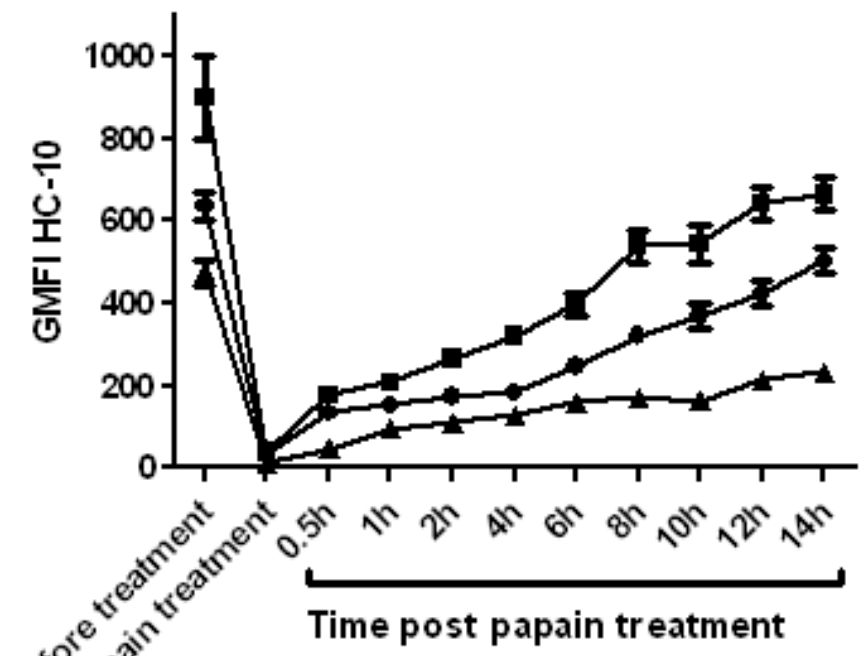

\section{$H L A-B * 27$ recovery in C1R transfectants}

(ME-1)

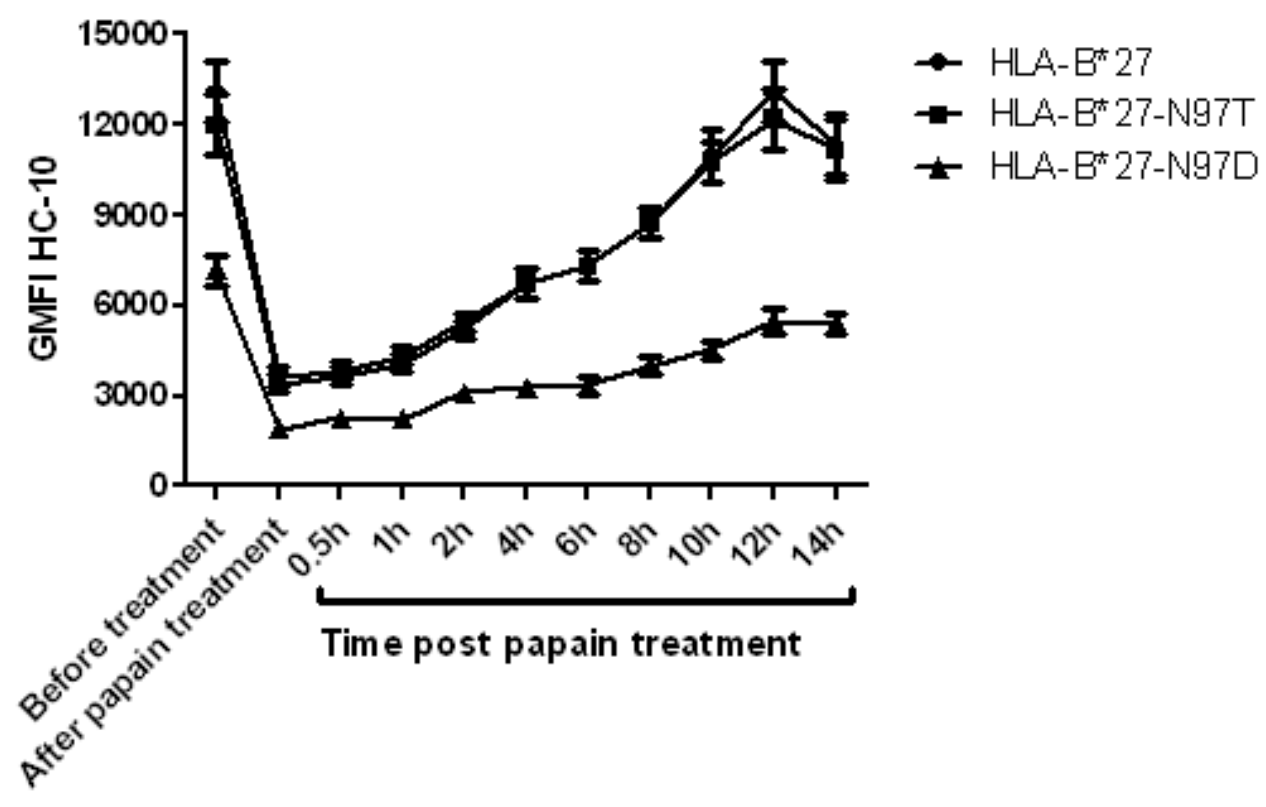

Figure S3. $\quad \mathrm{HLA}-\mathrm{B}^{*} 27$ N97T mutant free heavy chains are expressed the cell surface more rapidly than HLA-B*27. C1R cells expressing HLA-B*27, N97T or N97D mutants were treated with $4 \mathrm{mg} / \mathrm{ml}$ activated papain (10 mM Cystine, 30 minutes at $37^{\circ} \mathrm{C}$ ) for 30 minutes, then recovered in cell culture medium for 14 hours. Cells were stained using HC-10 (A) or ME-1 (B) for cell surface HLA-B*27 FHCs or classical complexes at different time points (before treatment, after papain treatment, $0.5 \mathrm{~h}, 1 \mathrm{~h}, 2 \mathrm{~h}, 4 \mathrm{~h}, 6 \mathrm{~h}, 8 \mathrm{~h}, 10 \mathrm{~h}, 12 \mathrm{~h}$ and $14 \mathrm{~h})$. The experiment was repeated three times, representative results are shown as mean and standard deviation. 
A

C1R transfectants

$\mathrm{HC}-10$

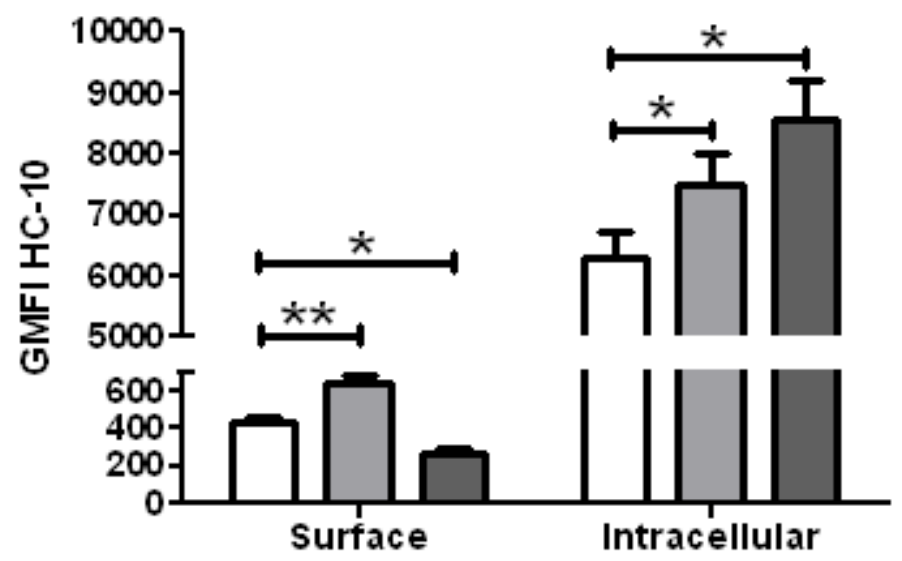

B

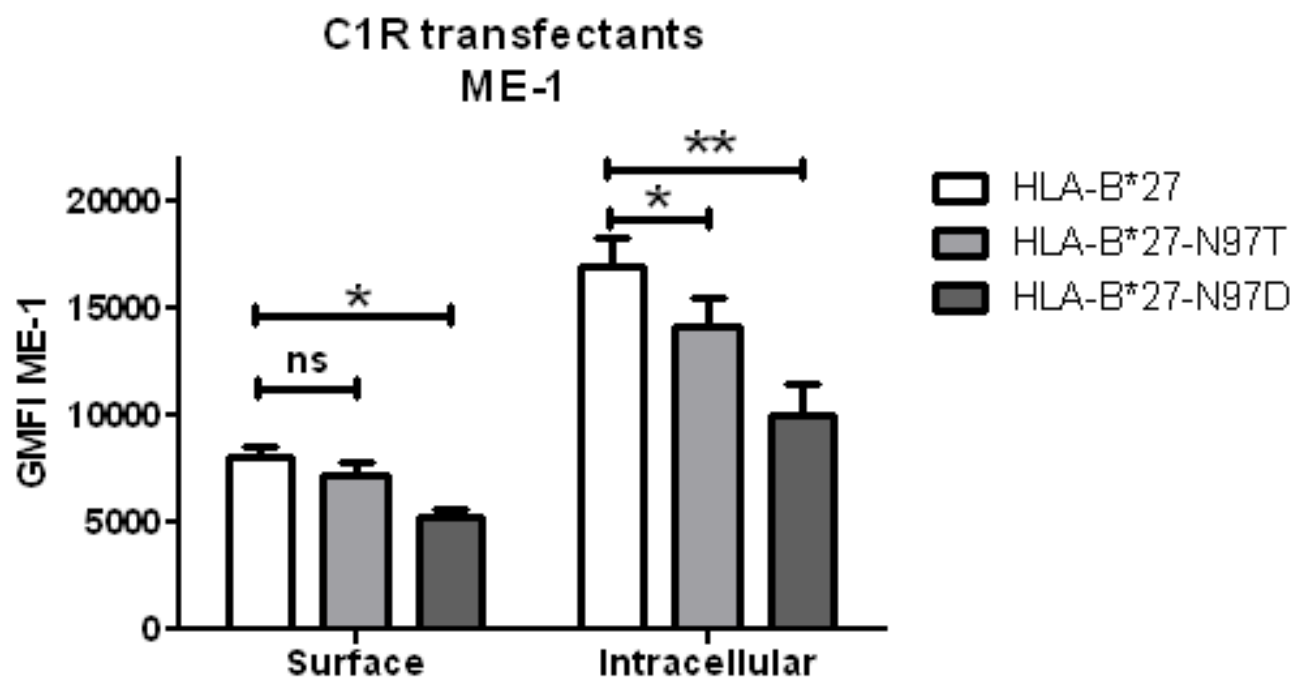

Figure S4. Comparison of intracellular HLA-B*27 expression levels between HLA-B*27, N97T and N97D mutants. C1R cells expressing HLA-B*27, N97T or N97D mutants were either cell surface or intracellularly stained using HC-10 (A) or ME-1 (B) for HLA-B*27 FHCs or classical complexes. The experiment was repeated three times, representative results are shown as mean and standard deviation. $P$ value was determined using unpaired two-tailed t-test $(*=p<0.05, * *=p<0.01)$. Of note, cell surface HLA-B*27 also contribute to intracellular staining, albeit to a smaller extent than intracellualr HLA-B*27 molecules. 


\section{$\beta 2 \mathrm{~m}-\mathrm{KO}$ HeLa cells}

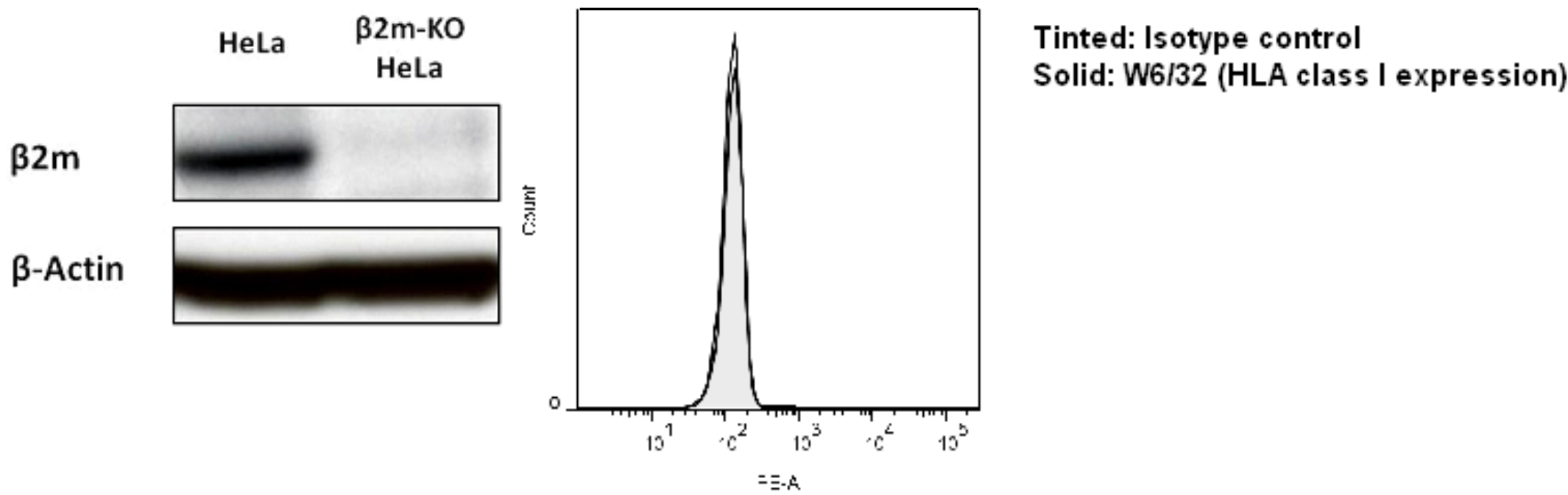

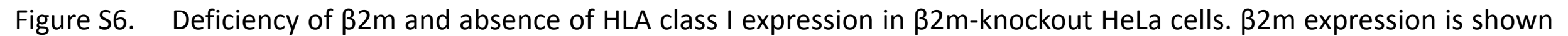
by western blot, HLA class I expression is shown by staining with W6/32 antibody. 
A

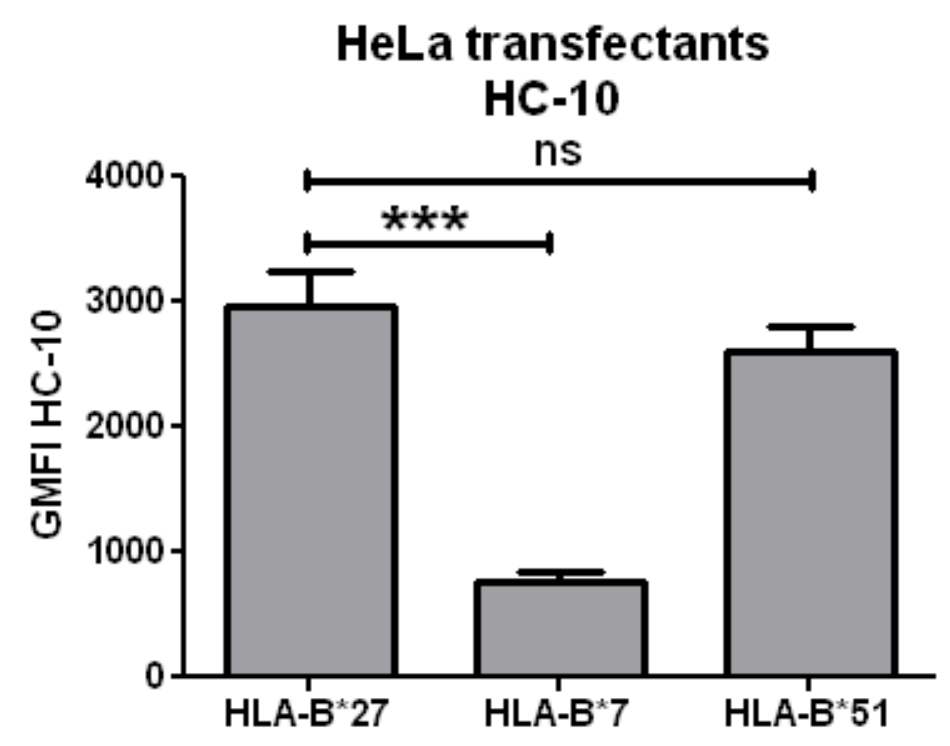

B

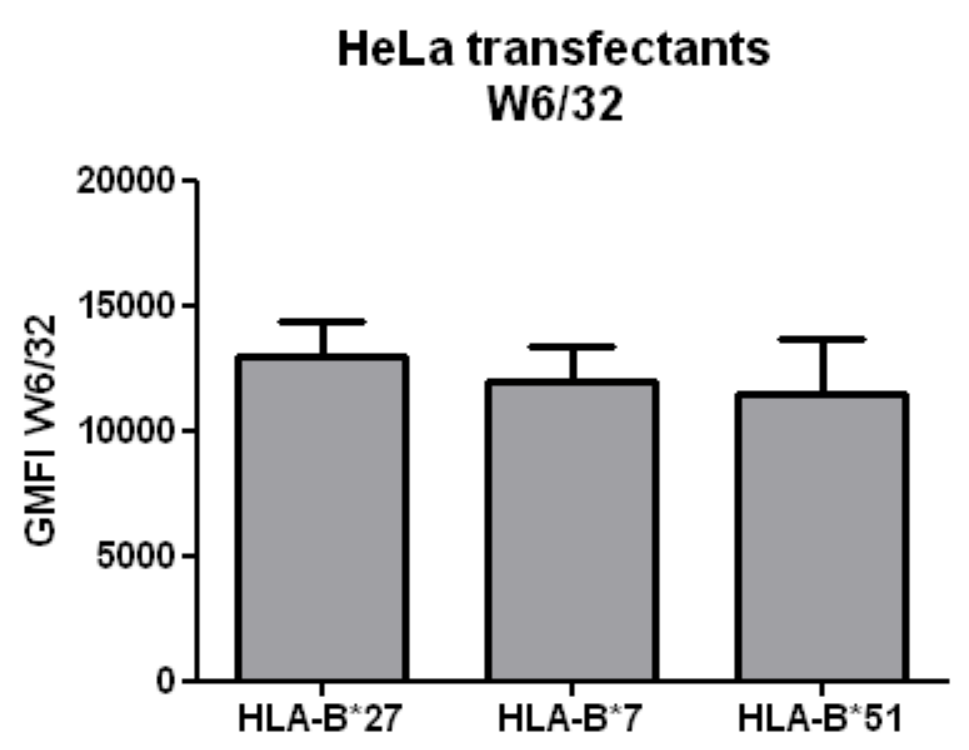

Figure S7. Comparison of HLA-B*27, HLA-B*7 and HLA-B*51 cell surface expression levels. Free heavy chain expression is measured using the HC-10 antibody (A). W6/32 antibody is used to measure classical HLA complexes (B). P value was determined using unpaired two-tailed t-test $(* * *=p<0.001$, ns $=$ not significant). The experiment was repeated three times. 